\title{
Spindle and Giant Cell Type Undifferentiated Carcinoma of the Proximal Bile Duct
}

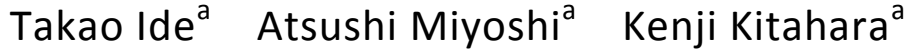 \\ Keita Kai ${ }^{a, b}$ Hirokazu Noshiro ${ }^{a}$ \\ Departments of ${ }^{a}$ Surgery and ${ }^{b}$ Pathology and Microbiology, Saga University \\ Faculty of Medicine, Saga, Japan
}

\section{Key Words}

Bile duct cancer - Bile duct resection - Adjuvant chemotherapy

\begin{abstract}
Undifferentiated spindle and giant cell carcinoma is an extremely rare malignant neoplasm arising in the extrahepatic bile duct. We herein present the case of a 67-year-old male who developed an undifferentiated spindle and giant cell carcinoma of the proximal bile duct. A nodular infiltrating tumor was located at the proximal bile duct, resulting in obstructive jaundice. Histologically, the tumor was composed of mainly spindle-shaped and giant cells and showed positive immunoreactivity for both cytokeratin and vimentin. Adjuvant chemotherapy was administered following extrahepatic bile duct resection, and he has been doing well for 16 months since the surgical treatment. The literature on this rare malignancy is also reviewed and discussed.
\end{abstract}

\section{Introduction}

Carcinosarcomas are rare malignant tumors composed of both carcinomatous and sarcomatous components intermingled with each other, and are divided into true and 'so-called' entities. True carcinosarcomas exhibit apparent differentiation, such as osteoid, rhabdoid or chondroid differentiation. Conversely, tumors that present both carcinomatous and sarcomatous components and undergo transitions between the two types of cells are known as so-called carcinosarcomas [1]. These tumors have previously been reported under a wide variety of names. According to the World Health Organization classification of tumors of the gallbladder and extrahepatic bile ducts, the latter tumor is defined as an undifferentiated carcinoma, spindle and giant cell type [2]. Although the majority of neoplasms occurring in the biliary tract are adenocarcinomas, the reported incidence of undifferentiated carcinoma is $0.38 \%$ of all gallbladder and extrahepatic bile duct cancers [3]. Moreover, this type of carcinoma is much more 
common in the gallbladder than in the bile duct. To the best of our knowledge, only 9 cases of spindle and giant cell type undifferentiated carcinoma arising in the extrahepatic bile duct have been reported in the English language literature [4-12].

We herein describe a further case of undifferentiated spindle and giant cell carcinoma of the proximal bile duct with interesting features. A review of the literature on this entity is also presented.

\section{Case Report}

A 67-year-old male was admitted to our hospital with jaundice and general fatigue. He had noticed white stool and brown urine 1 week prior to admission. He had no past history of liver or biliary disease. His laboratory data on admission were as follows: white blood cells $7,100 / \mu \mathrm{l}$, red blood cells $467 \times 10^{4} / \mu$ l, platelets $28.9 \times 10^{4} / \mu$ l, serum total bilirubin $14.0 \mathrm{mg} / \mathrm{dl}$ (normal $0.2-1.0$ ), serum direct bilirubin $10.3 \mathrm{mg} / \mathrm{dl}$ (normal $<0.3$ ), serum aspartate aminotransferase 496 IU/l (normal 10-35), alanine aminotransferase 1,080 IU/l (normal 5-40), lactate dehydrogenase $433 \mathrm{IU} / \mathrm{l}$ (normal 120-230), serum alkaline phosphatase 1,360 IU/l (normal 110-360), serum gamma-glutamyl transpeptidase 1,530 IU/l (normal 10-50), serum amylase 81 IU/l (normal 40-160), serum carcinoembryonic antigen $2.3 \mathrm{ng} / \mathrm{ml}$ (normal $0-5$ ), and serum carbohydrate antigen 19-9 $709 \mathrm{U} / \mathrm{ml}$ (normal <37). Computed tomography showed an enhanced mass with an unclear edge at the proximal bile duct, facing the right hepatic artery (fig. 1). Magnetic resonance cholangiopancreatography revealed stenosis of the common hepatic duct and bilateral intrahepatic duct dilatation (fig. 2). After hospitalization, an endoscopic nasobiliary drainage tube was inserted to decrease the hyperbilirubinemia and for treatment of presumptive cholangitis. A cytological examination of the drained bile juice identified malignant cells (adenocarcinoma). Under the preoperative diagnosis of proximal bile duct cancer, a hepatectomy of segments 1 and 4a combined with extrahepatic bile duct resection was scheduled because a further extended hepatectomy was concluded to be impossible due to the insufficient volume of the predicted future remnant liver, even if right portal vein embolization could be applied to increase the remnant liver volume.

The intraoperative findings showed a main tumor at the proximal bile duct, which adhered to the right hepatic artery too strongly to be ablated completely. Therefore, combined partial resection of the right hepatic artery was added to the resection of the extrahepatic bile duct for curative intent, and the distal remnant of the right hepatic artery was consequently anastomosed to the harvested right gastroepiploic artery in an end-to-end fashion. Since the intraoperative histological examination showed that the bile duct surgical margin was free from malignant cells, we judged that a caudate hepatic lobectomy was not required. However, a hepatectomy of segment 4 a was executed to make the reconstruction of the biliary tract easier. No distant metastasis or apparent lymph node metastasis was observed during the operation. Finally, we performed an extrahepatic bile duct resection with regional lymph node dissection, partial resection of the right hepatic artery, and a hepatectomy of segment $4 \mathrm{a}$.

The resected specimen showed a nodular infiltrating type tumor, measuring $1.7 \times 1.2 \mathrm{~cm}$ in diameter, at the proximal bile duct. Histopathologically, the tumor consisted of mainly spindle-shaped and giant cells, and moderately differentiated tubular adenocarcinoma cells were also recognized in some areas (fig. $3 a, b)$. The tumor extended down into the subserosa with perineural invasion, but showed neither vascular invasion nor lymph node metastasis. Immunohistochemical study revealed that the tumor cells were positive for cytokeratin 7 and vimentin (fig. 3c, d). On the basis of the aforementioned findings, the tumor was diagnosed to be undifferentiated carcinoma of the spindle and giant cell type.

The patient had a good postoperative course and was discharged on the 37th day after the operation. Adjuvant chemotherapy using gemcitabine was administered, and he has survived without recurrence for 16 months after the surgical treatment. 


\begin{tabular}{r|l|l|l}
$\begin{array}{r}\text { Case Reports in } \\
\text { Gastroenterology }\end{array}$ & $\begin{array}{l}\text { Case Rep Gastroenterol 2012;6:33-39 } \\
\text { DOI: 10.1159/000336198 }\end{array}$ & $\begin{array}{l}\text { Published online: } \\
\text { January 16, 2012 }\end{array}$ & $\begin{array}{l}\text { @ 2012 S. Karger AG, Basel } \\
\text { ISSN 1662-0631 } \\
\text { www.karger.com/crg }\end{array}$ \\
\hline
\end{tabular}

\section{Discussion}

In the present case, the tumor consisted of mainly spindle-shaped and giant cells without any apparent differentiation, showed both epithelial and mesenchymal immunoreactivities, and was finally diagnosed to be spindle and giant cell type undifferentiated carcinoma of the proximal bile duct. Only 9 cases of this type of undifferentiated carcinoma arising in the extrahepatic bile duct have been published in the English language literature (table 1).

The preoperative diagnosis of undifferentiated carcinoma of the extrahepatic biliary system is considered to be difficult because the exact diagnosis could not be reached before surgical intervention in the previously reported 9 cases as well as the present case. A polypoid or nodular configuration was shown in 9 of the 10 cases with undifferentiated carcinoma of the extrahepatic bile duct, including the present case. Therefore these tumors occluded the bile duct and caused obstructive jaundice in most of the cases, but these findings are not sufficient to differentiate between usual adenocarcinoma and undifferentiated carcinoma. Furthermore, there are no peculiar radiographic features reported so far associated with this neoplasm. If an exact preoperative diagnosis is requested to decide the treatment modality, a sufficient volume of biopsy specimen should be obtained.

In the literature, the prognosis of patients with undifferentiated carcinoma is very poor. The reported one-year survival rate for patients with undifferentiated carcinoma of the gallbladder was $18 \%$ [13], and the mean survival time for patients with undifferentiated carcinoma of the pancreas was estimated to be only 5 months [14]. The outcome of patients with this type of carcinoma of the extrahepatic bile duct is still uncertain because of the limited number of reported cases. In the 7 previous reports including follow-up studies, 2 patients died of postoperative complications (liver failure [5] and pulmonary infarction [10]) and 1 patient died 10 months after the operation due to local recurrence [6]. Nevertheless 4 patients were recurrence-free for 7-60 months since the surgical treatment $[4,7,8,11]$. The present patient has also been doing well for 16 months after the surgery. Hence, these outcomes seem to be better than those of the gallbladder and pancreas. The reason why patients with undifferentiated carcinoma of the extrahepatic bile duct have a relatively better prognosis may be due to the early appearance of jaundice, consequently such cases may be diagnosed at a resectable stage before further tumor progression. However, this does not necessarily mean that there is a better surgical outcome of undifferentiated carcinoma of the extrahepatic bile duct, because the durations of observation are not long enough in cases without disease relapse.

On the other hand, the recurrence-free cases showed a lack of any nodal involvement and a lack of any venous or lymphatic permeation. In contrast, the case that developed local recurrence had venous and lymphatic infiltration as well as perineural invasion, in spite of the fact that there was no metastasis to the regional lymph nodes [6]. This demonstrates that these invasion-related factors might be prognostic factors for patients with undifferentiated carcinomas. In our case, adjuvant chemotherapy was administered due to the detection of perineural invasion, and thus the patient has survived without recurrence since the surgical treatment, although continuation of careful follow-up is necessary. The most suitable adjuvant chemotherapeutic regimen is still the subject of much debate even for bile duct cancer, and this is the first report 
suggesting the possibility that a curative resection combined with adjuvant chemotherapy may contribute to prolonging the survival rate for this type of malignancy.

At present, there is no optimal therapy for undifferentiated carcinoma of the extrahepatic bile duct. A favorable prognosis can be expected with curative resection for the locally invasive cases of this type of carcinoma. However, surgical resection alone is not sufficient to produce a radical cure in cases with any nodal involvement or vessel invasion. Therefore, it is conceivable that multidisciplinary therapy, including chemotherapy and/or radiotherapy, might be indispensable for such cases. To approach the establishment of an optimal treatment for this type of carcinoma, a further accumulation of cases and discussions, as well as a better understanding of its biological features, is required.

Table 1. The reported cases of undifferentiated carcinoma, spindle and giant cell type, of the extrahepatic bile duct

\begin{tabular}{|c|c|c|c|c|c|c|c|c|c|}
\hline \multirow[t]{2}{*}{ No. } & \multirow[t]{2}{*}{ Year } & \multirow[t]{2}{*}{ Age } & \multirow[t]{2}{*}{ Sex } & \multirow[t]{2}{*}{ Symptoms } & \multicolumn{3}{|l|}{ Tumor } & \multirow{2}{*}{$\begin{array}{l}\text { Surgical } \\
\text { procedure }\end{array}$} & \multirow[t]{2}{*}{ Outcome } \\
\hline & & & & & location & size $(\mathrm{cm})$ & form & & \\
\hline 1 & 1994 & 52 & $\mathrm{~F}$ & pain, abdominal fullness & distal & 4.0 & polypoid & PD & 15 months, alive \\
\hline 2 & 1995 & 62 & M & pain, jaundice & hepatic hilus & 3.5 & nodular & ELHL & 10 days, dead \\
\hline 3 & 2000 & 81 & M & jaundice & middle & 9.2 & nodular & PPPD & 10 months, dead \\
\hline 4 & 2002 & 78 & M & general fatigue & distal & 1.0 & polypoid & PD & 15 months, alive \\
\hline 5 & 2003 & 71 & M & pain, jaundice & distal & 1.2 & nodular infiltrating & PD & 60 months, alive \\
\hline 6 & 2004 & 78 & $\mathrm{M}$ & pain, jaundice & distal & 4.0 & wall irregular & PD & ND \\
\hline 7 & 2007 & 59 & M & jaundice, abdominal fullness & hepatic hilus & 4.0 & nodular & RTH & 11 days, dead \\
\hline 8 & 2007 & 61 & M & pain, jaundice & middle & 4.8 & polypoid & PPPD & 7 months, alive \\
\hline 9 & 2010 & 65 & M & jaundice & middle & 1.5 & nodular & $\mathrm{PD}$ & ND \\
\hline 10 & $\begin{array}{l}\text { present } \\
\text { case }\end{array}$ & 67 & M & jaundice & proximal & 1.7 & nodular infiltrating & BDR & 16 months, alive \\
\hline
\end{tabular}

$\mathrm{BDR}=$ Extrahepatic bile duct resection; ELHL = extended left hepatic lobectomy; ND = no description; $\mathrm{PD}$ = pancreaticoduodenectomy; PPPD = pylorus-preserving pacreaticoduodenectomy; RTH = right trisection hepatectomy. 


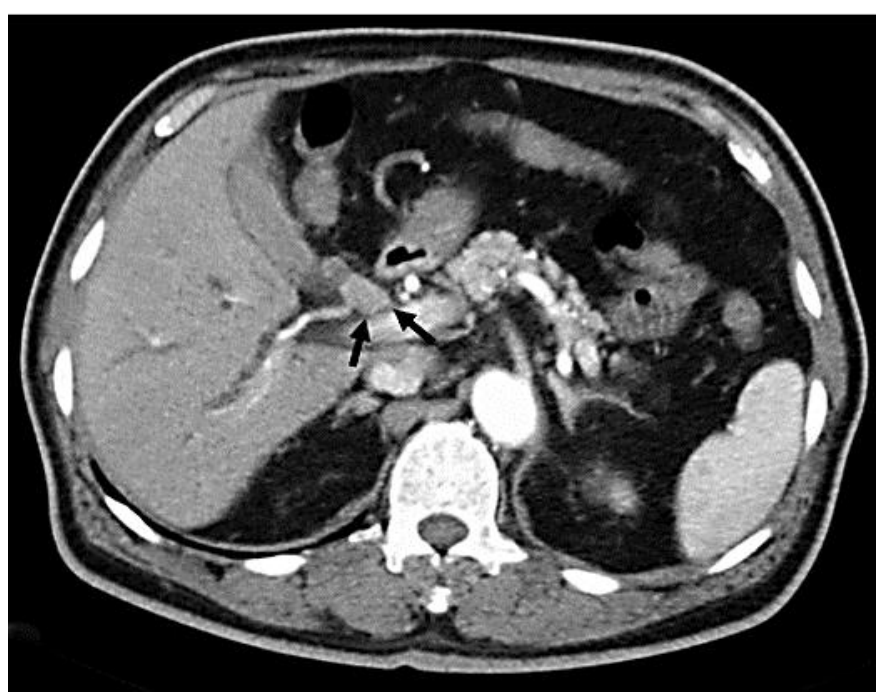

Fig. 1. Computed tomography revealed an enhanced mass at the proximal bile duct. Arrows indicate the mass lesion.

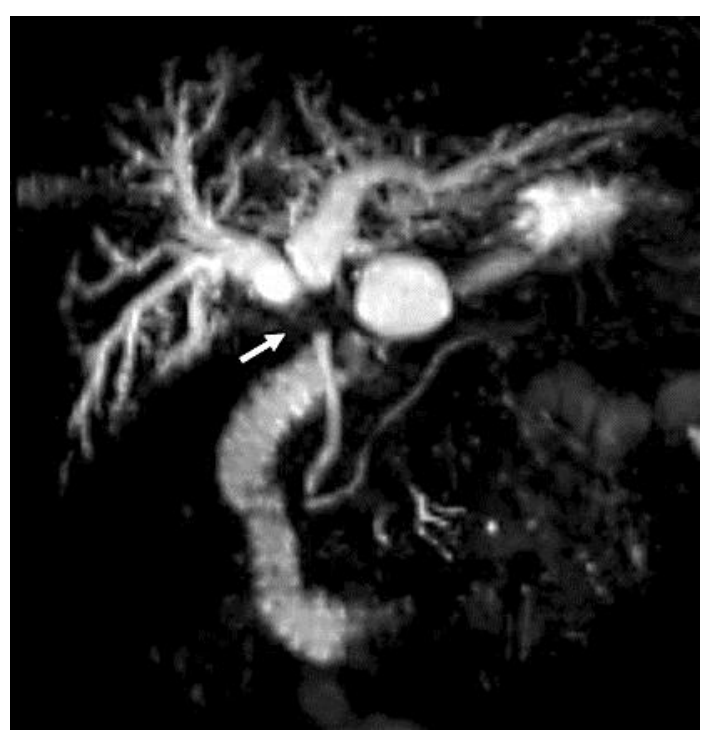

Fig. 2. Magnetic resonance cholangiopancreatography showed a stricture of the common hepatic duct (arrow) and dilatation of the bilateral intrahepatic ducts. 


\begin{tabular}{r|l|l|l}
$\begin{array}{r}\text { Case Reports in } \\
\text { Gastroenterology }\end{array}$ & $\begin{array}{l}\text { Case Rep Gastroenterol 2012;6:33-39 } \\
\text { DOI: 10.1159/000336198 }\end{array}$ & $\begin{array}{l}\text { Published online: } \\
\text { January 16, 2012 }\end{array}$ & $\begin{array}{l}\text { @ 2012 S. Karger AG, Basel } \\
\text { ISSN 1662-0631 } \\
\text { www.karger.com/crg }\end{array}$ \\
\hline
\end{tabular}

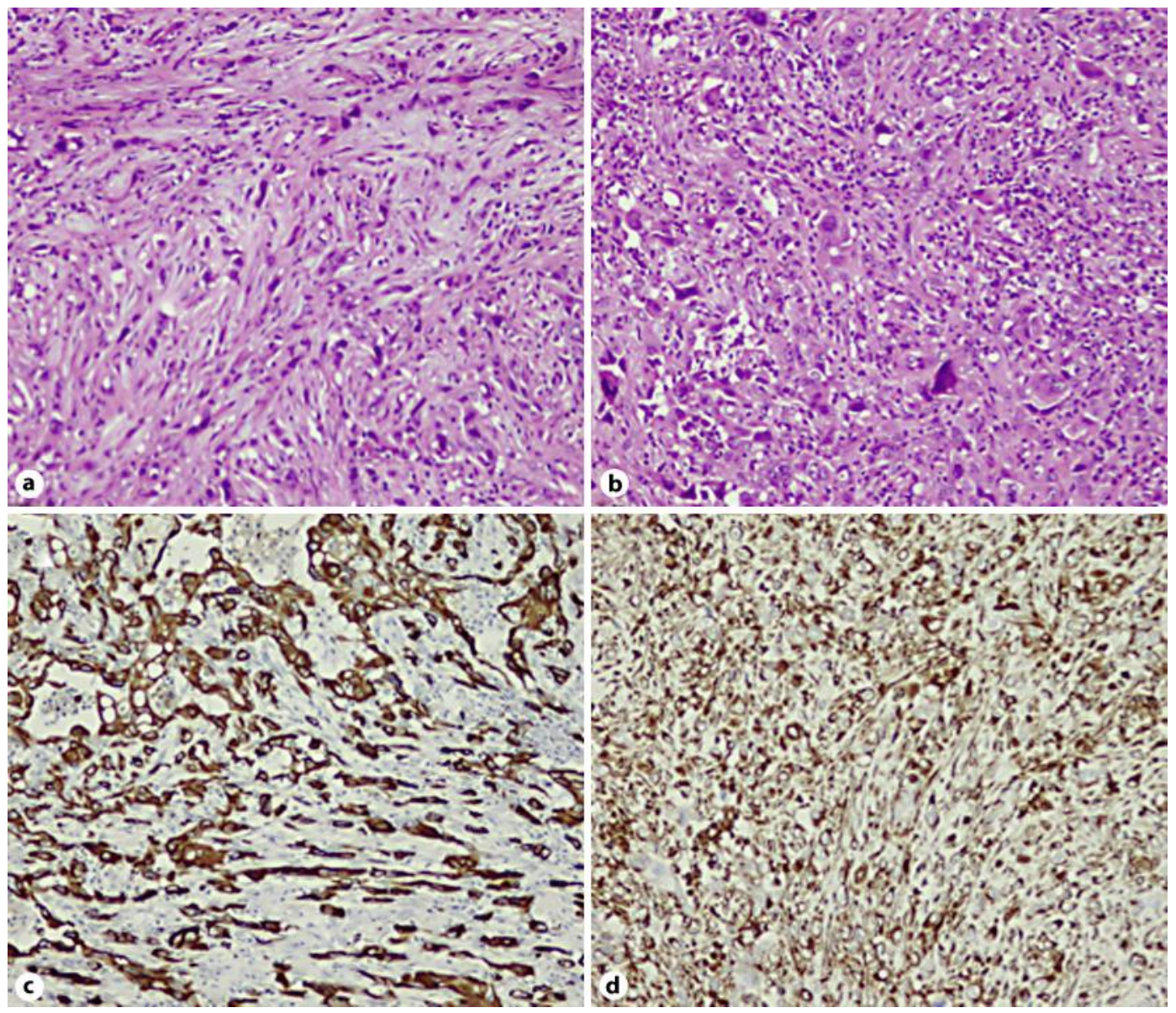

Fig. 3. The histopathological findings revealed that the tumor consisted of mainly spindle-shaped cells (a; H\&E, $\times 200)$. Giant cells were also recognized in some areas (b; H\&E, $\times 100)$. The tumor cells had positive immunoreactivity for cytokeratin $7($ c; $\times 200)$ and vimentin $(d ; \times 100)$.

\section{References}

1 Kadono J, Hamada N, Higashi M, Ishizaki N, Nakamura N, Sakata R: Carcinosarcoma of the extrahepatic bile duct. J Hepatobiliary Pancreat Surg 2005;12:328-331.

2 Hamilton SR, Aaltonen LA: World Health Organization Classification of Tumors. Pathology and Genetics of Tumors of the Digestive System. Lyon, IARC Press, 2000.

3 Albores-Saavedra J, Henson DE, Klimstra DS: Tumor of the gallbladder, extrahepatic bile ducts, and ampulla of Vater; in: Atlas of Tumor Pathology, Third series fascicle 27. Washington, D.C., Armed Forces Institute of Pathology, 2000.

4 Nonomura A, Mizukami Y, Matsubara F, Ueda H: A case of choledochal cyst associated with adenocarcinoma exhibiting sarcomatous features. J Gastroenterol 1994;29:669-675.

5 Yuan CY, Lo HW, Tseng CH, Takasaki T, Hanyu F: A case of spindle cell sarcomatous change of hepatic ducts manifesting as obstructive jaundice. J Gastroenterol 1995;30:264-267.

-6 Mokuno Y, Katoh T, Yoshida K, Abe T, Maeda M, Chigira H: Undifferentiated spindle cell carcinoma of the extrahepatic bile ducts. Hepatogastroenterology 2000;47:1234-1237.

7 Nagai E, Shinohara M, Yonemasu H, Kishikawa H, Tsuneyoshi M: Undifferentiated carcinoma of the common bile duct. J Hepatobiliary Pancreat Surg 2002;9:627-631. 
8 Dowaki S, Kijima H, Kashiwagi H, Tobita K, Ohtani Y, Sugio Y, Sekka T, Osamura Y, Imaizumi T, Makuuchi H: Undifferentiated spindle and giant cell carcinoma of the common bile duct. Tokai J Exp Clin Med 2003;28:127-130.

-9 Yoon GS, Choi DL: Sarcomatoid carcinoma of common bile duct. Hepatogastroenterology 2004;51: 106-109.

10 Nakanishi Y, Ito T, Kubota K, Takeda H, Yonemori A, Kawakami H, Zen Y, Kondo S: Spindle cell-type undifferentiated carcinoma of the common bile duct of the hepatic hilus: report of a case. Surg Today 2007;37:708-712.

11 Oikawa H, Oka K, Nagakura S, Fukunaga M, Sando N, Kashimura J, Hakozaki H: Spindle and giant cell type undifferentiated carcinoma arising in the common bile duct: a case report. Pathol Res Pract 2007;203:179-184.

12 Terada T: Spindle cell carcinoma of the common bile duct: case report with immunohistochemical analysis. Case Rep Gastroenterol 2010;4:374-380.

13 Guo K, Yamaguchi K, Enjoji M: Undifferentiated carcinoma of the gallbladder. A clinicopathologic, histochemical, and immunohistochemical study of 21 patients with a poor prognosis. Cancer 1988;61:1872-1879.

14 Maksymov V, Khalifa MA, Bussey A, Carter B, Hogan M: Undifferentiated (anaplastic) carcinoma of the pancreas with osteoclast-like giant cells showing various degree of pancreas duct involvement. A case report and literature review. JOP 2011;12:170-176. 